\title{
Atmospheric rivers emerge as a global science and applications focus
}

\section{Conference Paper}

\section{Author(s):}

Ralph, F. Martin; Dettinger, Michael D.; Lavers, David A.; Gorodetskaya, Irina V.; Martin, Andrew C.; Viale, Maximiliano; White, Allen B.; Oakley, Nina S.; Rutz, Jonathan J.; Spackman, J. Ryan; Wernli, Heini iD; Cordeira, Jason M.

Publication date:

2017-09

Permanent link:

https://doi.org/10.3929/ethz-b-000199081

Rights / license:

In Copyright - Non-Commercial Use Permitted

Originally published in:

Bulletin of the American Meteorological Society 98(9), https://doi.org/10.1175/BAMS-D-16-0262.1 


\title{
ATMOSPHERIC RIVERS EMERGE AS A GLOBAL SCIENCE AND APPLICATIONS FOCUS
}

\author{
F. M. Ralph, M. Dettinger, D. Lavers, I. V. Gorodetskaya, A. Martin, M. Viale, \\ A. B. White, N. Oakley, J. Rutz, J. R. Spackman, H. Wernli, and J. Cordeira
}

R ecent advances in atmospheric sciences and hydrology have identified the key role of atmospheric rivers (ARs) in determining the distribution of strong precipitation events in the midlatitudes. The growth of the subject is evident in the increase in scientific publications that discuss ARs (Fig. 1a). Combined with related phenomena, that is, warm conveyor belts (WCBs) and tropical moisture exports (TMEs), the frequency, position, and strength of ARs determine the occurrence of floods, droughts, and water resources in many parts of the world. A conference at the Scripps Institution of Oceanography in La Jolla, California, recently gathered over 100 experts in atmospheric, hydrologic, oceanic, and polar science; ecology; water management; and civil engineering to assess the state of AR science and to explore the need for new information. This first International Atmospheric Rivers Conference (IARC) allowed for much needed introductions and interactions across fields and regions, for example, participants came from five continents, and studies covered ARs in six continents and Greenland (Fig. 1b). IARC also fostered discussions of the status and future of $A R$ science, and attendees strongly supported the idea of holding another IARC at the Scripps Institution of Oceanography in the summer of 2018.

The concept of atmospheric rivers emerged in the 1990s (e.g., Zhu and Newell 1998) and at first received significant criticisms. However, with the advent of new satellite measurements of integrated water vapor (IWV) over the oceans and a set of field experiments during which research aircraft probed these features (Ralph et al. 2016), interest in the subject has grown.

\section{INTERNATIONAL ATMOSPHERIC RIVERS CONFERENCE}

What: The first conference dedicated to the subject of atmospheric rivers was held with over 100 attendees from across the globe discussing the science, impacts, and applications of atmospheric rivers including dynamics, observations, predictions, climate projections, and water decisions.

When: 8-II August 2016

Where: La Jolla, California

This growth is highlighted by the increase in publications using the term from fewer than 10 articles before 2004, when a publication by Ralph et al. (2004) combined research aircraft data, Special Sensor Microwave Imager (SSM/I) satellite IWV measurements, and the AR concept, to over 600 since then. Nonetheless, debate over the relationship between $\mathrm{AR}, \mathrm{WCB}$, and TME continues. It has been expressed by some that ARs, WCBs, and TMEs are the same thing, though the many papers, numerous funded proposals, doctoral dissertations and master's theses, and emerging applications of these various features of the midlatitude atmosphere indicate otherwise.

The 2016 IARC built upon an AR workshop in 2015 that had brought together about 30 scientists to help resolve the lingering questions about the relationship between AR, WCB, and TME. The 2015 workshop was organized by the new Center for Western Weather and Water Extremes (http://cw3e .ucsd.edu/) at the Scripps Institution of Oceanography at the University of California, San Diego. A 
brief workshop synopsis summarizing the discussions is available (Dettinger et al. 2015; http://cw3e .ucsd.edu/?p=2870). From independent analyses using differing methods, leaders on ARs, WCBs, and TMEs came to essentially the same conclusion, that is, that these phenomena are related but distinct. Two main activities emerged: 1) It was time to develop a comprehensive monograph on ARs, and 2) an open AR-focused conference was needed.

As a follow on to the IARC, which included the attendance of roughly 15 graduate students, it was decided to begin organizing a 3-week colloquium at the Scripps Institution of Oceanography in the future. It is intended to bring together the lead authors of the AR Monograph book chapters and graduate students from around the world for lectures, cross-disciplinary exchange, and mentored mini research efforts. IARC brought together most of the AR Monograph chapter authors at a point in the writing where new ideas garnered during the conference can be incorporated into the monograph.

IARC GOALS. The goals of the 2016 IARC were to

- evaluate the current state and applications of the science of the midlatitude atmospheric water cycle, with an emphasis on ARs and associated processes (e.g., WCB and TME);

- discuss differing regional perspectives;

AFFILIATIONS: RALPH AND MARTIN-Center for Western Weather and Water Extremes, Climate, Atmospheric Science, and Physical Oceanography, Scripps Institution of Oceanography, La Jolla, California; Dettinger-U.S. Geological Survey, Carson City, Nevada; LAVERS-European Centre for Medium-Range Weather Forecasts, Reading, United Kingdom; GORODETSKAYACentre for Environmental and Marine Studies, University of Aveiro, Aveiro, Portugal; VIALE-Universidad de Chile, Santiago, Chile; White and Spackman-Physical Sciences Division, National Oceanic and Atmospheric Administration/Earth System Research Laboratory, Boulder, Colorado; OAKLEY-Desert Research Institute, University of Nevada, Reno, Reno, Nevada; RutzWestern Region Headquarters, National Oceanic and Atmospheric Administration/National Weather Service, Salt Lake City, Utah; WERNLI-Institute for Atmospheric and Climate Science, ETH Zürich, Zürich, Switzerland; CORDEIRA-Plymouth State University, Plymouth, New Hampshire

CORRESPONDING AUTHOR: F. Martin Ralph, mralph@ucsd.edu

DOI:10.1I75/BAMS-D-16-0262.I

In final form 19 December 2016

(C)2017 American Meteorological Society

For information regarding reuse of this content and general copyright information, consult the AMS Copyright Policy.
- assess current forecasting capabilities; and - plan for future scientific and practical challenges.

IARC received 78 abstracts on ARs, their impacts, and applications of AR information to decisionmaking. Submissions represent work on six continents plus Greenland. The conference was attended by 105 people, which included invited presentations, oral sessions, a poster session, and panels on applications to decision-making, definitions of atmospheric river, and future directions. Breakout sessions discussed AR forecasting, AR Monograph chapters, and ARs in future climates and subseasonal to seasonal prediction.

Sessions were organized around the following themes, which represent AR Monograph sections:

- history of AR science;

- AR applications;

- global and regional perspectives;

- observing and detecting ARs;

- impacts of ARs;

- theory, structure, and processes; and

- modeling methodologies.

ATMOSPHERIC RIVER DEFINITION. One panel discussed the definition of atmospheric river. The moderator noted that the AR concept has brought greater focus on the horizontal transport component of the global water cycle and on our growing understanding of the roles that those transports play in extreme precipitation, water supplies, flooding, snow, drought, aqueous and terrestrial ecosystems, and geomorphology. However, AR science and definitions used in most studies today focus on midlatitudes, even though the concept of ARs is clearly reaching into, and called upon in, subtropical and polar regions as well. The following questions were posed to the panel and audience:

a) Should this definition be based on extratropical dynamics, or should it be broadened to represent areas of concentrated horizontal transport globally, with less of a requirement that it be associated with a particular set of dynamics?

b) The editor of the Glossary of Meteorology has been asked by members of the community for a definition of AR. What definition of an AR should we offer to the glossary? Or how should a formal definition be developed?

Attendees strongly favored maintaining the extratropical dynamics framework in the definition and supported holding town halls on the subject 
a) Scientific Literature discussing ARs

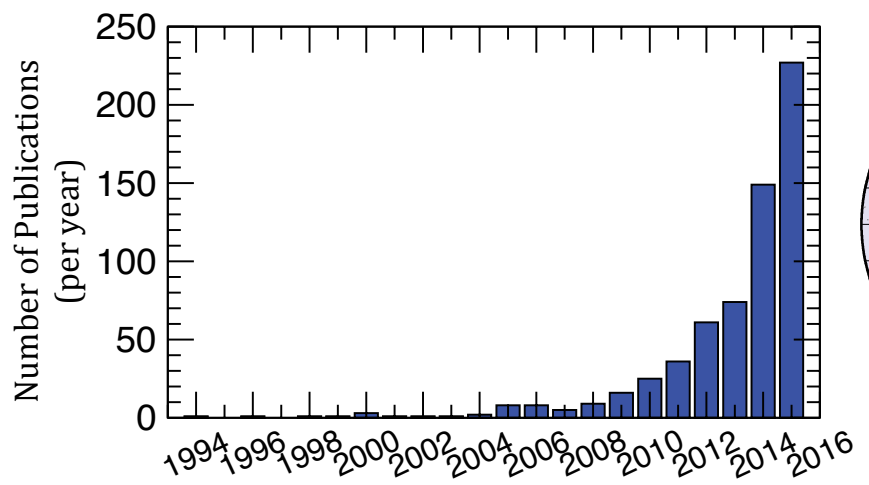

b) Locations of studies \& scientists at IARC

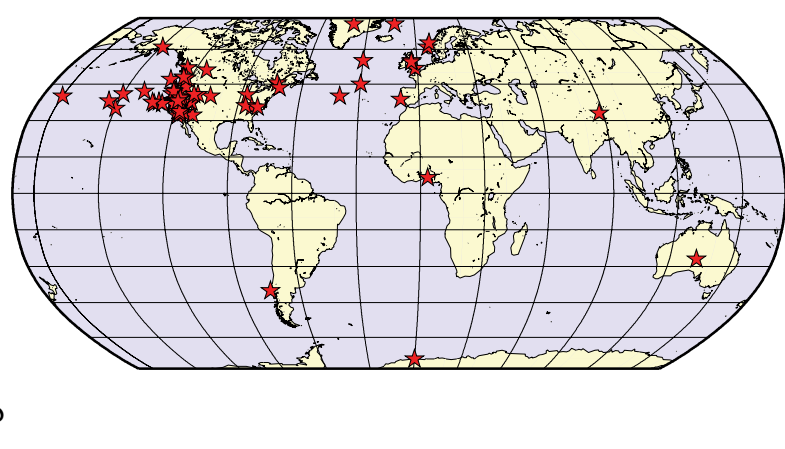

FIG. I. (a) Numbers of references to ARs in the scientific literature per year based on a combination of Google Scholar citations (verified by downloading and searching each for the term atmospheric river) and a literature search by a librarian at the NASA Jet Propulsion Laboratory for years prior to 2014 and Google Scholar search since then (total of 630 through 2015). (b) Approximate locations of conference participants or study areas of research reports at the conference.

at both the 2017 American Meteorological Society (AMS) Annual Meeting and American Geophysical Union (AGU) 2016 Fall Meeting. The Town Halls were then planned and carried out by the cochairs of the AMS Mesoscale Committee (Tom Galarneau), Hydrology Committee (John Eylander), and AR specialists (F. Martin Ralph and M. Dettinger).

Atmospheric rivers: A discussion of a definition for the Glossary of Meteorology. The Town Halls included a combined 10 panelists and over 150 attendees, who had a chance to offer opinions on the draft AR definition provided below. The comments were considered in the process of finalizing the definition which has now appeared in the Glossary of Meteorology.

ATMOSPHERIC RIVER DRAFT DEFINITION. An atmospheric river is a long, narrow, and transient corridor of anomalously strong horizontal water vapor transport that is typically located in the lowest $3 \mathrm{~km}$ of the troposphere and associated with a low-level jet stream ahead of the cold front of an extratropical cyclone. The water vapor in atmospheric rivers is supplied by tropical and/or extratropical moisture sources, and atmospheric rivers frequently lead to heavy precipitation where they intersect topographic or other lower-tropospheric boundaries or enter into the warm conveyor belt-related isentropic upward air motion. Atmospheric rivers conduct over $90 \%$ of all poleward water vapor transport in the extratropics in less than $10 \%$ of the zonal circumference of the globe.

SESSION SUMMARIES. AR observations. Satellitebased microwave radiometric measurements of integrated water vapor in ARs have been the foundation of AR monitoring over the oceans (Ralph et al. 2004; Wick et al. 2013). However, the microwave technique fails over land and ice surfaces because of their high and varying emissivities, and satellite methods cannot measure winds within ARs offshore, even though winds strongly control the water vapor transport and orographic precipitation enhancement upon AR landfall. However, two key methods are available now to measure horizontal water vapor transport in ARs: 1) atmospheric river observatories, which are an integrated system of ground-based remote sensing and in situ instruments that detect the forcings and impacts of ARs at a particular location (White et al. 2013), are now operating on the U.S. West Coast at seven locations; and 2) dropsondes released from aircraft offshore for example, during the multiyear CalWater program of field studies (Ralph et al. 2016).

AR dynamics. The IARC included two sessions related to theory, structure, and processes that govern the formation and intensity of ARs and their contained spatial and vertical distributions of water vapor and water vapor transport. The invited talk in the session investigated the interrelation of ARs in the life cycles of midlatitude cyclones and demonstrated the spatial overlap of ARs with TMEs (e.g., Knippertz and Wernli 2010) and the WCB (e.g., Carlson 1980). For example, large portions (50\%) of regions encompassed by ARs globally have a TME origin, whereas smaller portions (25\%) are related to a WCB or neither. These findings shed light on the processes that may form or maintain some ARs (TMEs) and lead to the dissipation of others (WCBs). 
$A R$ impacts. These two sessions discussed emerging studies of a broad range of effects of ARs on precipitation, floods, and other natural hazards and benefits, as well as strategies for communicating AR impacts. Strong ARs are increasingly known for yielding extreme orographic or warm conveyor belt precipitation that can cause major floods, effectively defining flood frequency regimes in many settings globally. The AR-related precipitation and floods have been widely addressed in the literature in terms of their significant impacts and costs; new studies are showing that ARs also trigger dangerous snow avalanches, landslides, debris flows, and damaging winds, often in the same uplands that yield the downstream floods. On the other hand, research highlights positive roles that ARs play in water resources, aquatic and terrestrial ecosystems and vegetation, seasonal snowpacks, and groundwater recharge. Finally, ARs critically affect the mass balances of the Antarctic and Greenland Ice Sheets, balances that will do much to define the extent and rate of sea level rise in centuries to come.

AR applications. The emerging understanding of ARs, from monitoring to dynamics and impacts, has led to a number of application areas, a few of which are highlighted here. A panel discussion focused on how AR information is affecting decision-making in water management and flood risk mitigation. These included perspectives from local, state, and federal water management experts who described how the development of AR science, monitoring, and forecasting tools offer opportunities to refine decisionmaking strategies related to reservoir operations. They also identified emerging areas of information needs, such as for subseasonal to seasonal predictions of precipitation in the western United States. Another major application area is evaluating climate change projections and documenting the key role of extreme events, especially those related to ARs, in determining annual precipitation. This included recognition of the risk of stronger ARs in future climate conditions where more water vapor is available due to warmer atmospheric conditions.

Student and early career perspectives. Roughly 20 graduate students and postdoctoral scholar attendees were invited to offer their personal perspectives on what has drawn them to the AR topic. The following motivations were described: i) AR research covers many scales of atmospheric motion and benefits from the study of pure atmospheric dynamics as well as applied research. This provides opportunities for people with a range of interests and talents. ii) Studying ARs offers opportunities for cross-disciplinary research, pairing meteorology with fields such as chemistry, geology, hydrology, climatology, civil engineering, and ecology. iii) ARs impact weather and climate in many areas, appealing to the student who observed their impacts while developing an interest in meteorology. iv) Finally, early-career researchers are motivated by a desire to make a difference through their work, and recognition that AR research presents a pathway for making scientific contributions that have a lasting impact on decision-making related to natural hazards, water resource management, and climate change has drawn them to the topic.

\section{FUTURE DIRECTIONS IN AR SCIENCE AND APPLICATIONS. Directions of future} research and applications were discussed, including development of an AR Monograph and summer colloquium, intercomparison of AR identification methods and criteria, quantification of water vapor sources and budgets through field campaigns, and assessments of ARs as key players in the global water cycle and heat and energy budgets.

ACKNOWLEDGMENTS. The IARC Organizing Committee thanks the California Department of Water Resources and the Scripps Institution of Oceanography's Center for Western Weather and Water Extremes for support, as well as the proactive group of graduate students and postdoctoral scholars, who provided invaluable logistical support throughout the conference.

\section{REFERENCES}

Carlson, T. N., 1980: Airflow through midlatitude cyclones and the comma cloud pattern. Mon. Wea. Rev., 108, 1498-1509, doi:10.1175/1520 -0493(1980)108<1498:ATMCAT>2.0.CO;2.

Dettinger, M., F. M. Ralph, and D. Lavers, 2015: Setting the stage for a global science of atmospheric rivers. Eos, Trans. Amer. Geophys. Union, 96, doi:10.1029 /2015EO038675.

Knippertz, P., and H. Wernli, 2010: A Lagrangian climatology of tropical moisture exports to the northern hemispheric extratropics. J. Climate, 23, 987-1003, doi:10.1175/2009JCLI3333.1.

Ralph, F. M., P. J. Neiman, and G. A. Wick, 2004: Satellite and CALJET aircraft observations of atmospheric rivers over the eastern North Pacific Ocean during the winter of 1997/98. Mon. Wea. Rev., 132, 1721-1745, doi:10.1175/1520-0493(2004)132<1721: SACAOO $>2.0 . \mathrm{CO} ; 2$. 
- , and Coauthors, 2016: CalWater field studies designed to quantify the roles of atmospheric rivers and aerosols in modulating U.S. West Coast precipitation in a changing climate. Bull. Amer. Meteor. Soc., 97, 1209-1228, doi:10.1175/BAMS -D-14-00043.1.

White, A., and Coauthors, 2013: A twenty-first-century California observing network for monitoring extreme weather events. J. Atmos. Oceanic Technol., 30, 1585-1603, doi:10.1175/JTECH-D-12-00217.1.
Wick, G. A., P. J. Neiman, and F. M. Ralph, 2013: Description and validation of an automated objective technique for identification and characterization of the integrated water vapor signature of atmospheric rivers. IEEE Trans. Geosci. Remote Sens., 51, 21662176, doi:10.1109/TGRS.2012.2211024.

Zhu, Y., and R. E. Newell, 1998: A proposed algorithm for moisture fluxes from atmospheric rivers. Mon. Wea. Rev., 126, 725-735, doi:10.1175/1520 -0493(1998)126<0725:APAFMF>2.0.CO;2.

\section{NEW FROM AMS BOOKS!}

"A thoughtful analysis of actions that we need to take to reduce the impacts of extreme weather... a must-read for everyone with an interest in the weather and climate."

- FRANKLIN W. NUTTER,

President, Reinsurance Association of America

\section{Living on the Real World: How Thinking and Acting Like Meteorologists Will Help Save the Planet} WILLIAM H. HOOKE

Meteorologists sift through a deluge of information to make predictions every day. Instead of being overwhelmed by the data and possibilities, they focus on small bits of information while using frequent collaboration to make decisions. With climate change a reality, William $\mathrm{H}$. Hooke suggests we look to the way meteorologists operate as a model for how we can solve the twenty-first century's most urgent environmental problems. 


\section{AMS BOOKS}

AMS MEMBERS GET FREE

\section{RESEARCH APPLICATIONS HISTORY}

CLIMATE

\section{The Thinking Person's Guide to Climate Change}

\section{ROBERT HENSON}

This fully updated and expanded revision of The Rough Guide to Climate Change combines years of data with recent research. It is the most comprehensive overview of climate science, acknowledging controversies but standing strong in its stance that the climate is changing-and something needs to be done.

(c) 2014, PAPERBACK, 520 PAGES, ISBN: 978-1-935704-73-7 LIST $\$ 30$ MEMBER $\$ 20$

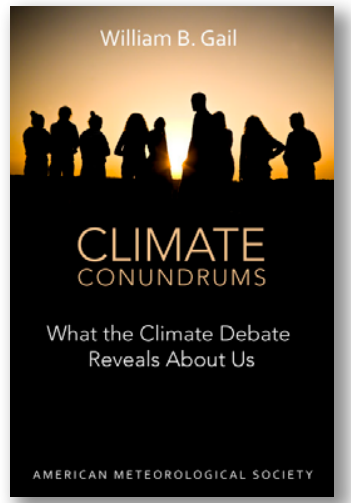

\section{Climate Conundrums:} What the Climate Debate Reveals about Us

\section{WILLIAM B. GAIL}

This is a journey through how we think, individually and collectively, about humanity's relationship with nature, and more. Can we make nature better? Could science and religion reconcile? Gail's insights on such issues help us better understand who we are and find a way forward.

(c) 2014, PAPERBACK, 240 PAGES, ISBN: 978-1-935704-74-4 LIST \$30 MEMBER \$20

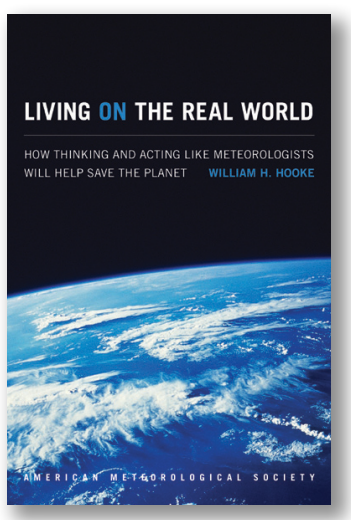

\section{Living on the Real World:} How Thinking and Acting Like Meteorologists Will Help Save the Planet WILLIAM H. HOOKE

Meteorologists focus on small bits of information while using frequent collaboration to make decisions. With climate change a reality, William $\mathrm{H}$. Hooke suggests we look to the way meteorologists operate as a model for how we can solve the 21st century's most urgent environmental problems.

\section{An Observer's Guide to Clouds} and Weather:

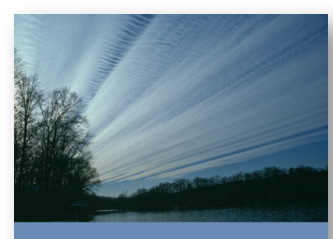

AN OBSERVER'S GUIDE

CLOUDS AND WEATHER

ANRTHEASTERN PRIMER ON PREDICTION

A Northeastern

Primer on Prediction

TOBY CARLSON, PAUL KNIGHT, AND CELIA WYCKOFF

With help from Penn State experts, start at the beginning and go deep. This primer intended for both serious enthusiasts and new meteorology students, will leave you with both refined observation skills and an understanding of the complex science behind the weather: the ingredients for making reliable predictions of your own. It connects fundamental meteorological concepts with the processes that shape weather patterns, and will make an expert of any dedicated reader.

(c) 2014, PAPERBACK, 210 PAGES,

ISBN: 978-1-935704-58-4 LIST \$30 MEMBER \$20

\section{Eloquent Science:}

A Practical Guide to Becoming a Better Writer, Speaker, and Atmospheric Scientist DAVID M. SCHULTZ

The ultimate communications manual for undergraduate and graduate students as well as researchers in the atmospheric sciences and their intersecting disciplines.

(c) 2009, PAPERBACK, 440 PAGES, ISBN 978-1-878220-91-2

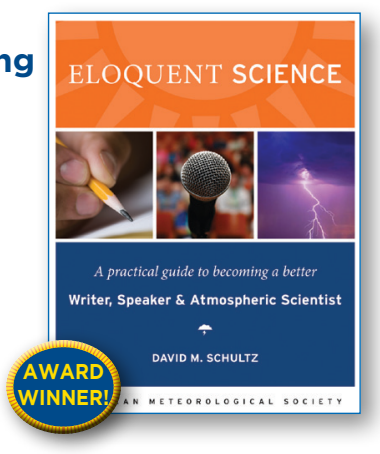

LIST \$45 MEMBER \$30

TEXTBOOK

\section{Midlatitude Synoptic Meteorology: Dynamics, Analysis, and Forecasting \\ GARY LACKMANN}

This textbook links theoretical concepts to modern technology, facilitating meaningful application of concepts, theories, and techniques using real data.

\section{(c)2011, PAPERBACK, 360 PAGES,} ISBN 978-1-878220-10-3 LIST \$100 MEMBER \$75 STUDENT MEMB. \$65

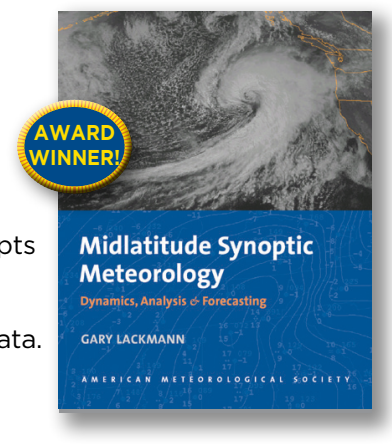

Midlatitude Synoptic Meteorology Teaching CD More than 1,000 PowerPoint Slides.

(c) 2013, CD, ISBN 978-1-878220-27-1 LIST \$100 MEMBER \$75 


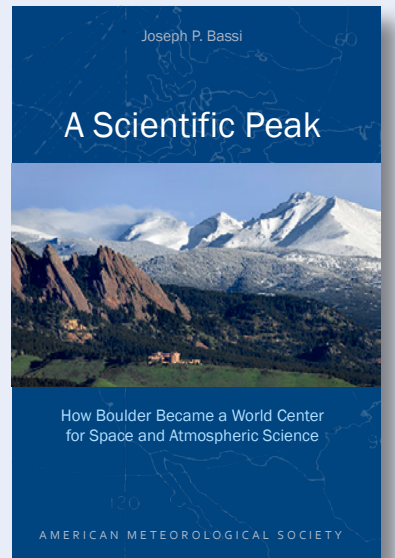

\section{A Scientific Peak:}

How Boulder Became a World Center for Space and Atmospheric Science

JOSEPH P. BASSI

How did big science come to Boulder, Colorado? Joe Bassi introduces us to the characters, including Harvard sun-Earth researcher Walter Orr Roberts, and the unexpected brew of politics, passion, and sheer luck that during the Cold War era transformed this "Scientific Siberia" to home of NCAR and NOAA.

(c) 2015, PAPERBACK, 264 PAGES, ISBN: 978-1-935704-85-0

LIST PRICE: $\$ 35.00$ MEMBER PRICE: $\$ 25.00$

METEOROLOGICAL MONOGRAPH SERIES

AMS Meteorological Monographs Vols. 1-55 (1947-2010) are available via Springer at springer.com/ams, with select volumes available in print via AMS at bookstore.ametsoc.org. Starting in 2016 with Vol. 56, new monographs will be open access, available via the AMS Journals Online site.

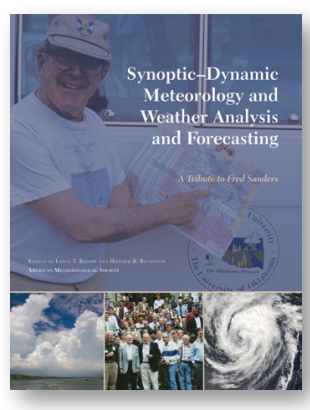

Synoptic-Dynamic Meteorology and Weather Analysis and Forecasting:

A Tribute to

Fred Sanders

EDITED BY LANCE F.

BOSART AND

HOWARD B. BLUESTEIN

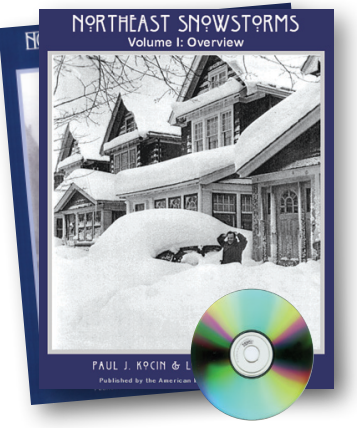

\section{Northeast} Snowstorms

(Volume I: Overview, Volume II: The Cases)

PAUL J. KOCIN AND LOUIS W. UCCELLINI

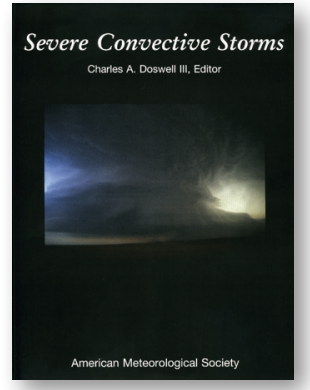

\section{Severe}

Convective

Storms

EDITED BY CHARLES A. DOSWELL III
HISTORY

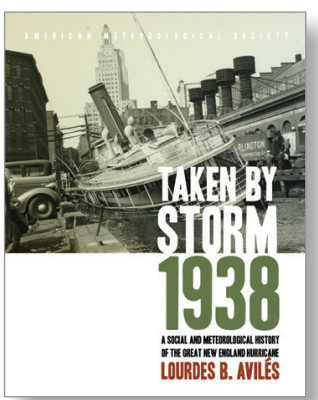

\section{Taken by} Storm, 1938:

A Social and Meteorological History of the Great New England Hurricane LOURDES B. AVILÉS

The science behind the 1938 Hurricane, which hit New England unannounced, is presented here for the first time along with new data that sheds light on the motivations of the Weather Bureau forecasters. This compelling history successfully weaves science, historical accounts, and social analyses to create a comprehensive picture of the most powerful and devastating hurricane to hit New England to date.

(c) 2013, HARDCOVER, 288 PAGES, ISBN: 978-1-878220-37-0 LIST $\$ 40$ MEMBER $\$ 30$

\section{Father Benito Viñes:}

The 19th-Century Life

and Contributions of a

Cuban Hurricane Observer and Scientist

\section{LUIS E. RAMOS GUADALUPE TRANSLATED BY OSWALDO GARCIA}

Before Doppler radar and weather broadcasts, Spanish Jesuit Benito Viñes (1837-1893) spent decades observing the skies at Belen Observatory in colonial Cuba. Nicknamed "the Hurricane Priest," Viñes taught the public about the weather and developed the first network of weather observation stations in the Caribbean, groundwork for the hurricane warning systems we use today.

(c) 2014, PAPERBACK, 172 PAGES

ISBN: 978-1-935704-62-1 LIST \$20 MEMBER \$16

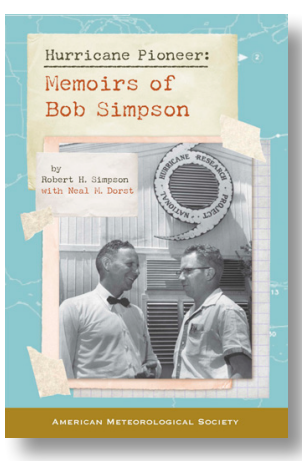

\section{Hurricane Pioneer:} Memoirs of Bob Simpson ROBERT H. SIMPSON AND NEAL DORST

In 1951, Bob Simpson rode a plane into a hurricane-just one of the many pioneering exploits you'll find in these memoirs. Bob and his wife Joanne are meteorological icons: Bob was the first director of the National Hurricane Research Project and a director of the National Hurricane Center. He helped to create the Saffir-Simpson Hurricane Scale; the public knows well his Categories 1-5. Proceeds from this book help support the AMS's K. Vic Ooyama Scholarship Fund.

(c) 2015, PAPERBACK, 156 PAGES

ISBN: 978-1-935704-75-1 LIST \$25 MEMBER \$20 
AMS titles now

available as eBooks

at springer.com

\section{AMS BOOKS}

\section{RESEARCH APPLICATIONS HISTORY}

www.ametsoc.org/amsbookstore

黛 Springer

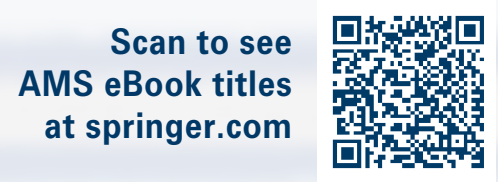

Springer

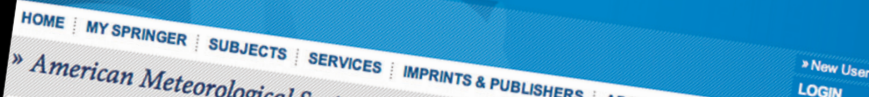

"American Meteorological SOCiety
"AOMTIN

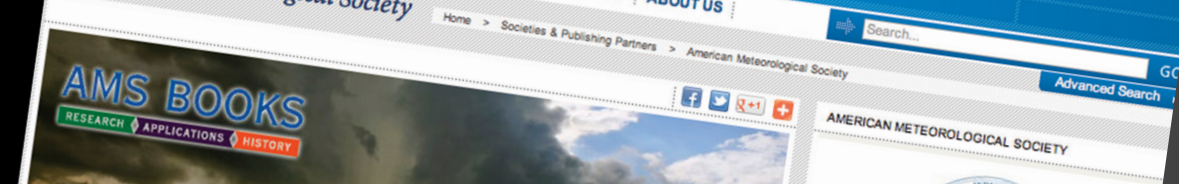

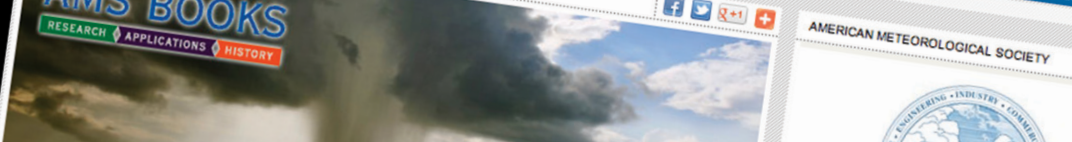

American Meteorol

Promoting the dewerogical Society

the atmos the deverap

the atmospheric and ralent and disseminatb of

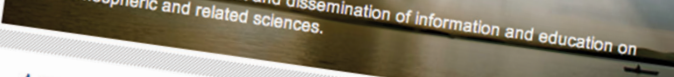

American Meteorological Society eB

AMS Books

published by the AMs a monograph publishing prent

shing program related o ho poer-

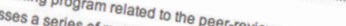

related to the as eBooks) as weil ar ariy out-ortprint vol metoorological and historica journals

to the atmospheric sciences a growing list of academis, which have been urough ographs

ind policy, and general-interest books

Sort listing by:

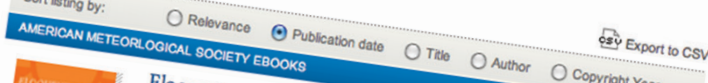

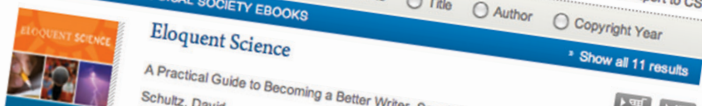

Scholta, David

एक्ष 15

Price from $\$ 45.00$

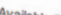

